\title{
Violencia hacia las mujeres: de género sin ningún género de dudas
}

\section{Violence against women: it is a gender violence without any doubt}

\author{
Blanca Obón-Azuaraa,b, Ángel Gasch Gallén b,c, Isabel Gutiérrez-Cíaa,b \\ a Servicio de Medicina Intensiva, Hospital Clínico Universitario de Zaragoza, España \\ b Grupo Interdisciplinar Independiente de Estudios de Género Aragón (GRIIEGA), España \\ ${ }^{\mathrm{C}}$ Departamento de Fisiatría y Enfermería, Facultad de Ciencias de la Salud, Universidad de Zaragoza, España
}

ए n 2019, la Junta de Andalucía puso en marcha un teléfono de atención para las víctimas de la "violencia intrafamiliar" (Noticias de la Junta de Andalucía, 2020), con la idea de discernir entre violencia de género e intrafamiliar, considerando que a esta última no se le estaba prestando una respuesta adecuada y específica por parte de los poderes públicos.

Según Etienne et al. (2002), la violencia familiar se define como los malos tratos o agresiones físicas, psicológicas, sexuales o de otra índole, infligidos por personas del medio familiar y que se dirigen generalmente a los miembros más vulnerables del mismo (niños, mujeres y ancianos). La violencia de género hace referencia a la violencia específica contra las mujeres, utilizada como instrumento para mantener la discriminación, la desigualdad y las relaciones de poder de los hombres sobre las mujeres. Comprende la violencia física, sexual y psicológica, incluidas las amenazas, la coacción, o la privación arbitraria de libertad, que ocurre en la vida pública o privada y cuyo principal factor de riesgo lo constituye el hecho de ser mujer.

Es cierto que el elemento fundamental que define a ambas violencias es distinto: en el caso de la violencia de género es la víctima, la mujer; y en el de la violencia intrafamiliar es el contexto, el ámbito del hogar (Maqueda, 2006). No obstante, no se puede ignorar que ambas violencias tienen únicamente una raíz de género, como una estructura de desigualdad específica contra las mujeres que representa una situación de poder que se ejerce, reconoce y legitima a favor de los hombres.

Por todo ello, aunque se trate de una maniobra política, resulta imposible eliminar el término y el constructo de "género", ya que el elemento fundamental es la propia motivación de este tipo de violencia, que tiene que ver con el propio hecho de ser mujer (Ley Orgánica 1/2004).
Resulta muy llamativo que todo ello parta de una Consejería de Igualdad de un Gobierno Autonómico, ya que el hecho de invisibilizar la violencia de género y abordar la violencia en el ámbito intrafamiliar como una situación distinta y excluyente constituye un grave problema. Al relativizar su origen, se coloca a las mujeres en una situación de vulnerabilidad, al igual que a otros miembros del eje familiar. Además, genera una desinformación, confusión entre la población y graves barreras para el desarrollo del conocimiento científico sobre un problema de salud pública tan importante.

No se debe olvidar que el problema real que sustenta ambas violencias es únicamente una cuestión de género, que se interseca con diferentes ejes de desigualdad (Jiménez Carrillo, 2020) y que valida la posición dominante de los hombres en las relaciones interpersonales (Connell, 2013) debido a la persistencia de una estructura patriarcal en nuestra sociedad actual (Lázaro Castellanos, 2017).

Este abordaje que no tiene en cuenta de manera específica la violencia de género no resulta ético, pues comporta un ambiente de invisibilización de la violencia y una pérdida de oportunidades para las intervenciones comunitarias que favorezcan la igualdad desigualdad (Jiménez Carrillo, 2020). También contribuye al establecimiento de barreras para el desarrollo de estrategias inclusivas como la educación para la salud y la educación afectiva y sexual, que son capaces de prevenir la violencia por razones de género y de modificar los factores comunitarios y sociales que influyen en la misma (Redding, 2017; García Díaz, 2018).

\section{Agradecimientos}

Concepción Tomás-Aznar, que tanto nos ha inspirado siempre. 


\section{Referencias bibliográficas}

Connell, R. W. (2013). Gender and power: Society, the person and sexual politics. John Wiley \& Sons.

Etienne, G., Krug, E.G., Dahlberg, L.L., Mercy, J.A., Zwi, A.B., \& Lozano, R. (2002). World report on violence and health. Geneva: World Health Organization.

García Díaz, V. (2018). Actitudes sexistas y reconocimiento del maltrato en parejas jóvenes Atención Primaria, 50(7), 398-405. Doi: https://doi.org/10.1016/j. aprim.2017.04.001

Lázaro Castellanos, R. (2017). Interseccionalidad del género y mercado de trabajo postfordista. La Ventana. Revista de Estudios de Género. 5(46), 202-243. Recuperdo de: http://www.scielo. org. $\mathrm{mx} /$ scielo.php?script=sci_arttext\&pid=S140594362017000200202\&lng=es\&nrm=iso\&tlng=es

Ley orgánica 1/2004, de 28 de diciembre, de Medidas de Protección Integral contra la Violencia de Género. $B O E, 313$. Recuperado de: https://www.boe.es/eli/es/ lo/2004/12/28/1/con

Jiménez Carrillo, M. (2020). ¿Refleja la historia clínica electrónica los determinantes sociales de la salud desde Atención Primaria? Atención Primaria, 53(1), 36-42. Doi: https://doi.org/10.1016/j. aprim.2020.01.007

Maqueda Abreu, M.L. (2006). La violencia de género: Entre el concepto jurídico y la realidad social. Revista Electrónica de Ciencia Penal y Criminología, 8.

Noticias de la Junta de Andalucía. (2020). Rocío Ruiz presenta la línea 900300 003, que facilitará la comunicación de este tipo de casos para que los servicios sociales desarrollen actuaciones que garanticen la seguridad. Recuperado de: http:// www.juntadeandalucia.es/presidencia/portavoz/ social/155319/telefono/atencion/informacion/ violenciaintrafamiliar/Consejeriadelgualdad/ RocioRuiz

Redding, E.M. (2017). Gender inequality and violence against women in Spain, 2006-2014: towards a civilized society. Gaceta Sanitaria, (31), 82-88. 